\title{
Fatal anaphylaxis registries data support changes in the who anaphylaxis mortality coding rules
}

\author{
Luciana Kase Tanno ${ }^{1,2,3^{*}}$, F. Estelle R. Simons ${ }^{4}$, Isabella Annesi-Maesano ${ }^{3}$, Moises A. Calderon ${ }^{5}$, Ségolène Aymé , \\ Pascal Demoly ${ }^{2,3}$, on behalf of the Joint Allergy Academies
}

\begin{abstract}
Anaphylaxis is defined as a severe life-threatening generalized or systemic hypersensitivity reaction. The difficulty of coding anaphylaxis fatalities under the World Health Organization (WHO) International Classification of Diseases (ICD) system is recognized as an important reason for under-notification of anaphylaxis deaths. On current death certificates, a limited number of ICD codes are valid as underlying causes of death, and death certificates do not include the word anaphylaxis per se. In this review, we provide evidences supporting the need for changes in WHO mortality coding rules and call for addition of anaphylaxis as an underlying cause of death on international death certificates. This publication will be included in support of a formal request to the WHO as a formal request for this move taking the $11^{\text {th }}$ ICD revision.
\end{abstract}

Keywords: Anaphylaxis, Classification, International Classification of Diseases, Mortality, World Health Organization

\section{Background}

\section{Anaphylaxis definition and epidemiology}

Definitions of anaphylaxis for clinical use by healthcare professionals all state the concepts of a serious, generalized, allergic or hypersensitivity reaction that can be lifethreatening and even fatal [1]. In all countries, epidemiological and health services research can serve as a baseline for quality improvement, prioritization of anaphylaxis programs, and eventual reduction in morbidity and mortality.

Publications on anaphylaxis epidemiological data have increased in the past few years due to the need to understand the status and evolution of this disease more precisely worldwide, improve in order to plan national or global actions to support better management and prevention globally and nationally, and support education and awareness. Data can differ widely depending on a number of variables. For instance, European data have indicated incidence rates for all-cause anaphylaxis ranging from 1.5 to 7.9 per 100000 person/year, with an estimation that $0.3 \%$ ( $95 \%$ CI $0.1-0.5)$ of the population

\footnotetext{
* Correspondence: luciana.tanno@gmail.com

${ }^{1}$ Hospital Sírio Libanês, São Paulo, Brazil

2University Hospital of Montpellier, Montpellier, France

Full list of author information is available at the end of the article
}

will experience anaphylaxis at some point during their lifetime [2]. On the other hand, it is estimated that 1 in every 3000 inpatients in US hospitals suffer from an anaphylactic reaction with a risk of death around $1 \%$, accounting for 500 to 1000 deaths annually in this country [3].

In public health terms, anaphylaxis is considered to be an uncommon cause of death [4-9]. The case fatality rate is difficult to ascertain with accuracy. Accurate anaphylaxis mortality data are hampered by the limited recognition of this condition among health professionals, the absence of historical details from eyewitnesses, incomplete death scene investigations, paucity of specific pathologic findings at postmortem examination, and the under-notification of anaphylaxis $[9,10]$.

\section{Vital statistics: historical background and current standard methods}

The first International List of Causes of Death was drafted by Jacques Bertillon and colleagues in 1885. It was prepared based on the principle of distinguishing between systemic diseases and those localized to a particular organ or anatomical site, and officially adopted for use in mortality registries in 1893 [11]. This 
classification, which was accepted by many countries and has been periodically revised, constituted the basis of the International Classification of Diseases (ICD). Anaphylaxis was not included in the original list because it was not formally described until 1902 [12]. Although a well-known cause of death, particularly in the fields of allergy and emergency medicine, anaphylaxis has never been appropriately classified in the different versions of the ICD, and has never been considered an underlying cause of death on death certificates.

Mortality statistics are widely used for medical research, monitoring of public health, evaluating health interventions and planning and follow-up of health care. Analysis of mortality data typically involves comparisons of data sets. However, unless the data have been compiled using the same methods and according to the same standards, comparisons potentially yield misleading results. For these reasons, the World Health Organization (WHO) issued international instructions on data collection, coding and classification, and statistical presentation of causes of death. In most countries, mortality statistics are routinely compiled according to regulations and recommendations adopted by the World Health Assembly (WHA). The international mortality coding instructions presuppose that data have been collected with a death certificate conforming to the International form of medical certificate of cause of death (Fig. 1) [13]. It is the responsibility of the medical practitioner or other qualified certifier signing the death certificate to indicate which morbid conditions led directly to death and to state any antecedent conditions giving rise to this cause.

The international death certificate form is split in 2 parts (Fig. 1). Part 1 is for diseases or conditions related to the sequence of events leading directly to death, and Part 2 is for unrelated but contributory conditions. The terminal cause of death is the condition entered first on the first line of Part 1 of the death certificate. The underlying cause of death is the condition selected for such single-cause tabulation. In most cases, the underlying cause of death is the same as the starting point of the sequence described in Part 1. Special coding instructions on specific sequences and ICD categories may have the effect that a condition other than the starting point is selected as the underlying cause of death for use in the vital statistics [13].

If an apparent error is found in the mortality data notification, it should be reported to the WHO, which will either explain the rationale or take steps to correct the error at the international level. Individual countries should not correct what is assumed to be an error, since changes at the national level will lead to data that are not comparable to data from other countries, and thus less useful for analysis [13].

\section{Anaphylaxis mortality data: unmet needs Allergic and hypersensitivity conditions in the ICD-11}

Anaphylaxis mortality epidemiological data are sparse. Besides the different methods used and the different populations studied (Table 1), the lack of standardized definitions for this condition in the WHO ICD $[1,10,14]$ is a recognized challenge for the development of accurate and comparable population-based vital statistics in the field.

Causes of deaths are classified and grouped according to the ICD edition in use at the time, currently ICD-10 (and adaptations), and the information on vital statistics is collected using the international form recommended by the WHO. However, on the current death certificates, a limited number of ICD-10 codes are considered to be valid for representing underlying causes of death. As an example, research showed an under-notification of anaphylaxis deaths due to difficult coding under the ICD-10

\begin{tabular}{|c|c|c|}
\hline & Cause of death & $\begin{array}{c}\text { Approximate interval } \\
\text { between onset and death }\end{array}$ \\
\hline \multicolumn{3}{|l|}{ Part I } \\
\hline $\begin{array}{l}\text { Disease or condition directly } \\
\text { leading to death * }\end{array}$ & $\begin{array}{l}\text { (a) } \\
\text { Due to (or as a consequence of) }\end{array}$ & \\
\hline \multirow{3}{*}{$\begin{array}{l}\text { Antecedent causes } \\
\text { Morbid conditions, if any, giving rise to } \\
\text { the above cause, stating the underlying } \\
\text { condition last }\end{array}$} & (b) & \\
\hline & (c) & \\
\hline & (d) & \\
\hline \multicolumn{3}{|l|}{ Part II } \\
\hline $\begin{array}{l}\text { Other significant conditions contributing } \\
\text { to the death, but not related to the } \\
\text { disease or condition causing it }\end{array}$ & & \\
\hline
\end{tabular}

Fig. 1 The World Health Organization's International form of medical certificate of cause of death 


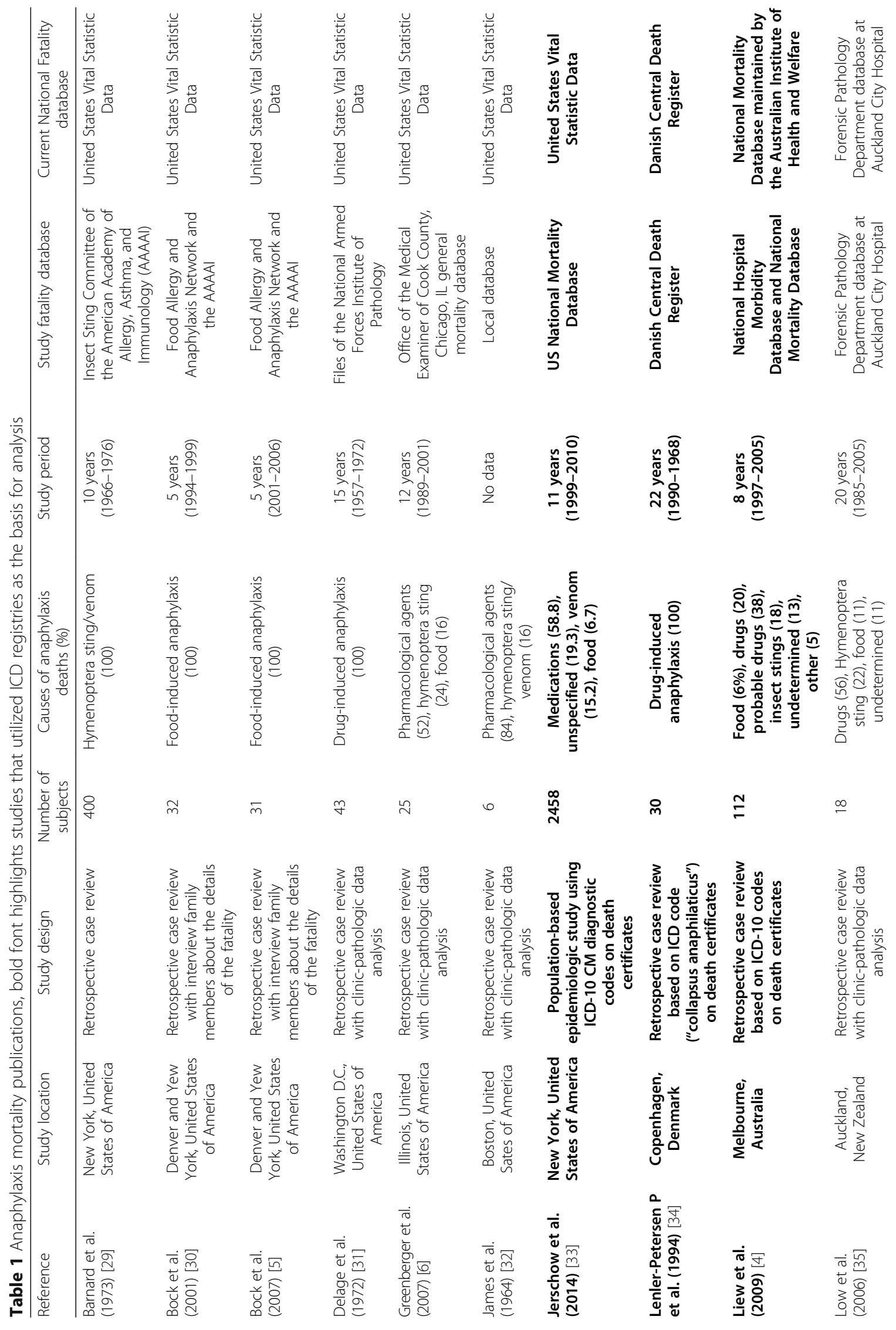




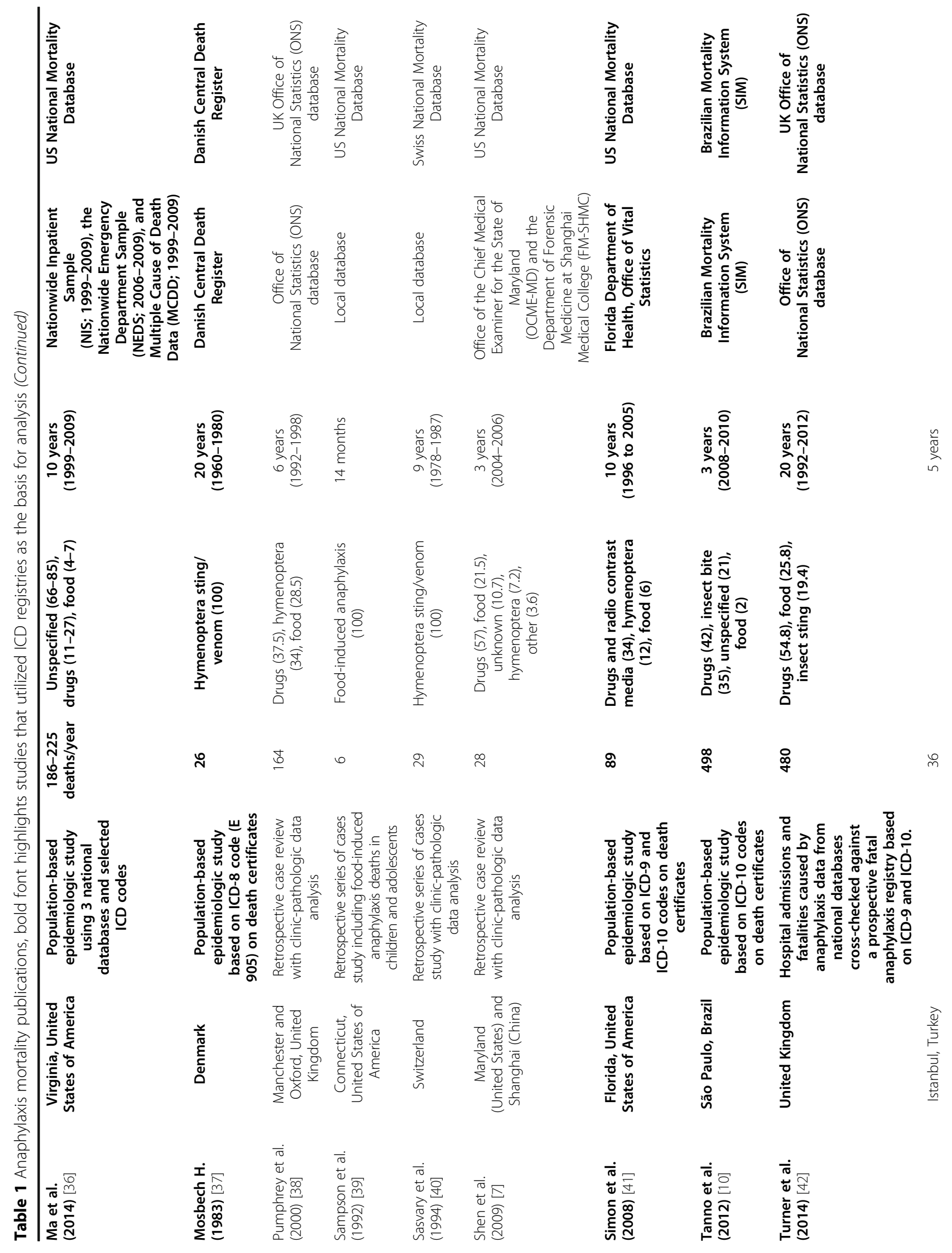




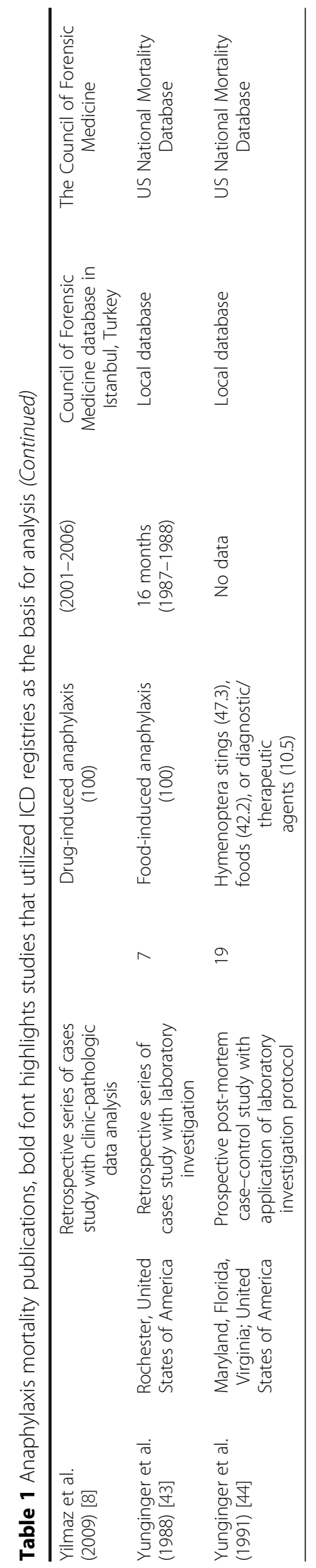


using the Brazilian national mortality database, given that there are no anaphylaxis-specific ICD-10 codes which are considered valid for coding underlying causes-of-death [10].

Taking the window of opportunity presented by the ongoing ICD-11 revision, the under-notification of death data [10] triggered a cascade of strategic international actions supported by the Joint Allergy Academies and the ICD WHO governance [15-25] to update the classifications of allergic conditions for the new ICD edition. These efforts have resulted in the construction of the new "Allergic and hypersensitivity conditions" section under the "Disorders of the Immune system" chapter $[21,26]$.

Here, in order to deliberate the new frame and follow the ICD-11 revision agenda, we reviewed the forms on which anaphylaxis has been classified in the ICD and the published anaphylaxis fatalities data, particularly with regards to the methods used for death notification. We also propose modifications in the WHO mortality coding rules under the $11^{\text {th }}$ revision of the ICD context.

\section{Status of anaphylaxis in the ICD-10 and the ICD-11 Beta draft}

The search for the term "anaphylaxis" in the online versions of the ICD-10 (2016 version) [27] and of the ICD11 Beta draft Linearization (July 2016 version) [26] allows us to demonstrate the main differences resulted from all the efforts over the last 4 years (Fig. 2). The ICD-10 inherited the hierarchical scheme of the previous ICD versions, essentially based in main organs or main cause (infectious diseases or external causes). Therefore, some systemic conditions such as anaphylaxis were adjusted in the chapter related to external causes. As a result of our search into the ICD-10 (2016 version) platform, we have addressed the "XIX Injury, poisoning and certain other consequences of external causes" chapter, specifically the "T78 Adverse effects, not elsewhere classified" section. In Fig. 2 (highlighted in red) we also underline the lack of awareness of allergic and hypersensitivity concepts verified in the T78 section. Under this section it is possible to observe that only severe cases of anaphylaxis have been prioritized (T78.2 Anaphylactic shock), which was classified at the same level of "Anaphylactic shock due to adverse food reaction", "Angioneurotic oedema" and "Allergy, unspecified". In fact, obstruction of the upper and/or lower respiratory tract leading to respiratory distress and potential fatality is more commonly observed in anaphylaxis than hypotension and shock per se. It is also possible to note the misclassification implied in the ICD-10 exemplified by scattering "T78.2 Anaphylactic shock" at the same level of the "T78.3 Angioneurotic oedema", "T78.4 Allergy, unspecified" and "T78.9 Adverse effect, unspecified" under the same heading (Fig. 2, in bold).
In the new "Allergic and hypersensitivity conditions" section of ICD-11, it was possible to build a sub-section specifically addressed to anaphylaxis. For the first time, anaphylaxis is elected as individualized conditions into the ICD-11 frame, receiving a sub-section addressed to this condition. Currently, this subsection contains 7 main anaphylaxis headings to be post-coordinated with severity and causality classification/specifications, still under tuning. The building block of this framework was the result of combined efforts and constant discussions with the groups of experts and the ICD WHO governance.

Based on the ICD-10 codes, some external stimuli are considered as underlying causes-of-death, but the word anaphylaxis as such has never been listed as an underlying cause-of-death. In fact, having allergic and hypersensitivity conditions classified in a more detailed scheme in the ICD-11 and not as in ICD-10 into a specific chapter in the "External causes of morbidity and mortality" or in the "Injury, poisoning and certain other consequences of external causes" chapters allows for capture of more realistic anaphylaxis mortality data from now on.

\section{What do the published fatal anaphylaxis data tell us?}

Constructing a classification of anaphylaxis for ICD-11 was a challenge; however, it was important to align this with the published post-mortem anaphylaxis epidemiological data. From $30^{\text {th }}$ June 2015 to $4^{\text {th }}$ December 2015, thirty manuscripts were selected using PubMed Mesh terms "anaphylaxis deaths", "anaphylaxis mortality", "anaphylaxis fatalities", covering documents published in the last five decades. We did not include case reports as such (with the exception of a few landmark case series), studies in animal models or reviews. All publications were independently evaluated by two co-authors and disagreements related to the inclusion into the analysis were resolved through open discussion. We analyzed methodological aspects, main outcomes and databases used in the remaining 22 publications (Table 1), 45\% of which focused on specific triggers or etiology. Most of these documents (64\%) were published over the last 15 years. The methods used and the population evaluated varied among the publications; however, $54.5 \%$ focused on US populations in different centers. Overall, $54 \%$ were based on national databases and $36.4 \%$ of these documents used the ICD for mortality registries as the basis of the analysis (as highlighted in bold in Table 1), with $62.5 \%$ being population-based studies. Based on ICD registries, regardless of the ICD version used, $87.5 \%$ of all the studies had to utilize secondary data in death certificates in order to capture the anaphylaxis data. Studies of anaphylaxis mortality using secondary data require the use of information derived from the underlying as well as the contributing cause-of- 


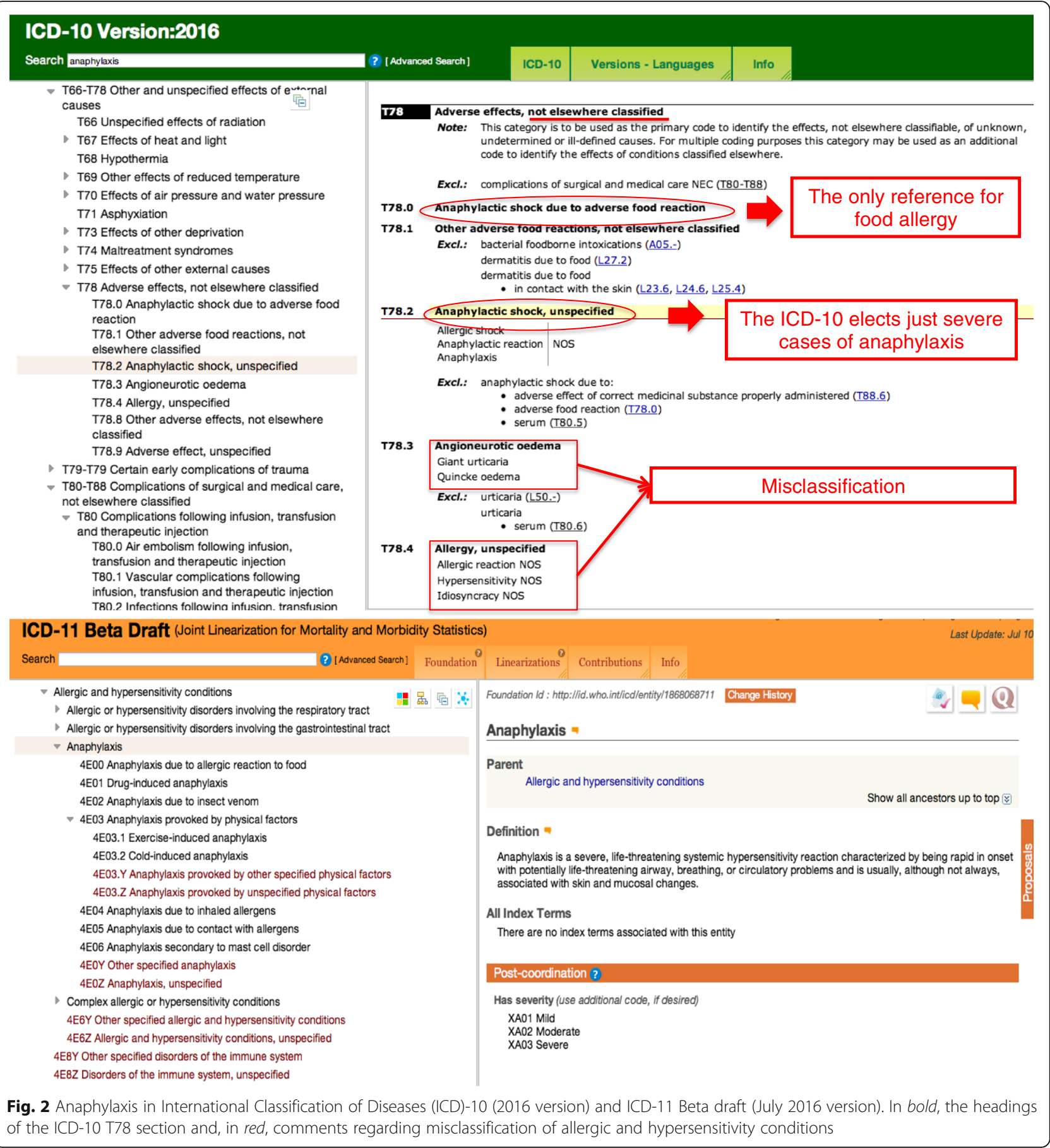

death. In other words, none of these deaths would have been found had the authors exclusively considered information from the underlying cause-of-death field.

\section{Conclusion}

Data support changes in the world health organization anaphylaxis mortality coding rules

In summary, in this manuscript, we provide evidence that supports the need for changes in the WHO mortality coding rules by adding anaphylaxis as an underlying cause of death in international death certificates. This article is a contribution to the establishment of ICD-11 to ensure a proper coding of anaphylaxis, in order to generate an accurate knowledge of the consequences of this severe condition. This document will comprise part of a formal request to the WHO to change mortality coding rules so that anaphylaxis can be listed as an underlying cause of death in international death certificates. 
Once implemented by the WHO, there will be two immediate consequences of the use of the new classification based on the logic of the ICD-11: (i) although currently anaphylaxis fatalities are perceived as rare, the reported number of anaphylaxis deaths may increase [28] and (ii) most cases will be included in official mortality statistics, providing a global standard for comparability and, therefore, for decision-making and prevention.

\section{Abbreviations}

ICD: International Classification of Diseases; WHA: World Health Assembly; WHO: World Health Organization

\section{Acknowledgement}

We are extremely grateful to all the representatives of the ICD-11 revision with whom we have been carrying on fruitful discussions, helping us to tune the here presented classification: Robert Jakob, Linda Best, Nenad Kostanjsek, Robert J G Chalmers, Jeffrey Linzer, Linda Edwards, Ségolène Ayme, Bertrand Bellet, Rodney Franklin, Matthew Helbert, August Colenbrander, Satoshi Kashii, Paulo E. C. Dantas, Christine Graham, Ashley Behrens, Julie Rust, Megan Cumerlato, Tsutomu Suzuki, Mitsuko Kondo, Hajime Takizawa, Nobuoki Kohno, Soichiro Miura, Nan Tajima and Toshio Ogawa. We acknowledge the assistance provided by Lori McNiven, Health Sciences Centre, Winnipeg, MB, Canada. Joint Allergy Academies: American Academy of Allergy Asthma and Immunology (AAAAl), European Academy of Allergy and Clinical Immunology (EAACI), World Allergy Organization (WAO), American College of Allergy Asthma and Immunology (ACAAl), Asia Pacific Association of Allergy, Asthma and Clinical Immunology (APAAACI), Latin American Society of Allergy, Asthma and Immunology (SLAAI).

\section{Funding}

Not applicable.

\section{Availability of data and materials}

Data sharing not applicable to this article as no datasets were generated or analyzed during the current study.

\section{Authors' contributions}

LKT and PD contributed to the construction of the document (designed the study, analyzed and interpreted the data, and wrote the manuscript). FERS contributed to the anaphylaxis fatality references, and with SA, IA-M, MAC, contributed to tuning the document and revision of the manuscript. All authors read and approved the final manuscript.

\section{Competing interests}

The authors declare that they do not have any competing interests related to the contents of this article.

\section{Consent for publication}

Not applicable.

\section{Ethics approval and consent to participate}

Not applicable.

\footnotetext{
Author details

${ }^{1}$ Hospital Sírio Libanês, São Paulo, Brazil. ${ }^{2}$ University Hospital of Montpellier, Montpellier, France. ${ }^{3}$ Sorbonne Universités, UPMC Paris 06, UMR-S 1136, IPLESP, Equipe EPAR, 75013 Paris, France. ${ }^{4}$ Section of Allergy \& Clinical Immunology, Department of Pediatrics \& Child Health, University of Manitoba, Winnipeg, Canada. ${ }^{5}$ Section of Allergy and Clinical Immunology, National Heart and Lung Institute, Royal Brompton Hospital, Imperial College London, London, UK. ${ }^{6}$ NSSERM, US14, Paris, France.
}

Received: 2 September 2016 Accepted: 13 December 2016 Published online: 13 January 2017

\section{References}

1. Simons FER, Ardusso LR, Bilò MB, Cardona V, Ebisawa M, El-Gamal YM, et al. International consensus on (ICON) anaphylaxis. World Allergy Organ J. 2014:7:9.

2. Panesar SS, Javad S, de Silva D, Nwaru Bl, Hickstein L, Muraro A, Roberts G, Worm M, Bilò MB, Cardona V, Dubois AE, Dunn Galvin A, Eigenmann P, Fernandez-Rivas M, Halken S, Lack G, Niggemann B, Santos AF, Vlieg-Boerstra BJ, Zolkipli ZQ, Sheikh A, on behalf of the EAACI Food Allergy and Anaphylaxis Group. The epidemiology of anaphylaxis in Europe: a systematic review. Allergy. 2013;68:1353-61.

3. Neugut Al, Ghatak AT, Miller RL. Anaphylaxis in the United States: an investigation into its epidemiology. Arch Intern Med. 2001;161:15-21.

4. Liew WK, Williamson E, Tang ML. Anaphylaxis fatalities and admissions in Australia. J Allergy Clin Immunol. 2009;123:434-42.

5. Bock SA, Muñoz-Furlong A, Sampson HA. Further fatalities caused by anaphylactic reactions to food, 2001-2006. J Allergy Clin Immunol. 2007;119:1016-8.

6. Greenberger PA, Rotskoff BD, Lifschultz B. Fatal anaphylaxis: postmortem findings and associated comorbid diseases. Ann Allergy Asthma Immunol. 2007;98:252-7.

7. Shen Y, Li L, Grant J, Rubio A, Zhao Z, Zhang X, Zhou L, Fowler D. Anaphylactic deaths in Maryland (United States) and Shanghai (China): A review of forensic autopsy cases from 2004 to 2006. Forensic Sci Int. 2009;186:1-5.

8. Yilmaz R, Yuksekbas O, Erkol Z, Bulut ER, Arslan MN. Postmortem findings after anaphylactic reactions to drugs in Turkey. Am J Forensic Med Pathol. 2009;30:346-9.

9. Simons FE, Ardusso LR, Bilò MB, El-Gamal YM, Ledford DK, Ring J, et al. World allergy organization guidelines for the assessment and management of anaphylaxis. World Allergy Organ J. 2011;4(2):13-37.

10. Tanno LK, Ganem F, Demoly P, Toscano CM, Bierrenbach AL. Undernotification of anaphylaxis deaths in Brazil due to difficult coding under the ICD-10. Allergy. 2012;67:783-9.

11. Moriyama IM, Loy RM, Robb-Smith AHT. History of the statistical classification of diseases and causes of death. Rosenberg HM, Hoyert DL, eds. Hyattsville, MD: National Center for Health Statistics. 2011. https:/www. cdc.gov/nchs/data/misc/classification_diseases2011.pdf. Accessed Dec 2016.

12. Portier $P$, Richet $C$. De l'action anaphylactique de certains venins. C R Séances Soc Biol. 1902;54:170.

13. World Health Organization, International Classification of Diseases website. cited, available: http://www.who.int/classifications/icd/en/. Accessed Jul 2016.

14. Muraro A, Roberts G, Worm M, Bilò MB, Brockow K, Fernández Rivas M, Santos AF, Zolkipli ZQ, Bellou A, Beyer K, Bindslev-Jensen C, Cardona V, Clark AT, Demoly P, Dubois AE, DunnGalvin A, Eigenmann P, Halken S, Harada L, Lack G, Jutel M, Niggemann B, Ruëff F, Timmermans F, Vlieg-Boerstra BJ, Werfel T, Dhami S, Panesar S, Akdis CA, Sheikh A, on behalf of the EAACI Food Allergy and Anaphylaxis Guidelines Group. Anaphylaxis: guidelines from the European Academy of Allergy and Clinical Immunology. Allergy. 2014;69:1026-45.

15. Tanno LK, Calderon MA, Goldberg BJ, Akdis CA, Papadopoulos NG, Demoly P. Categorization of allergic disorders in the new World Health Organization International Classification of Diseases. Clin Transl Allergy. 2014;4:42.

16. Demoly P, Tanno LK, Akdis CA, Lau S, Calderon MA, Santos AF, et al. Global classification and coding of hypersensitivity diseases - An EAACl - WAO survey, strategic paper and review. Allergy. 2014;69:559-70.

17. Tanno LK, Calderon MA, Goldberg BJ, Gayraud J, Bircher AJ, Casale T, et al. Constructing a classification of hypersensitivity/allergic diseases for ICD-11 by crowdsourcing the allergist community. Allergy. 2015;70:609-15.

18. Tanno LK, Calderon M, Papadopoulos NG, Demoly P. Mapping hypersensitivity/allergic diseases in the International Classification of Diseases (ICD)-11: cross-linking terms and unmet needs. Clin Transl Allergy. 2015;5:20.

19. Tanno LK, Calderon MA, Demoly P, on behalf the Joint Allergy Academies Making allergic and hypersensitivity conditions visible in the International Classification of Diseases-11. Asian Pac Allergy. 2015;5:193-6.

20. Tanno LK, Calderon MA, Demoly P, on behalf the Joint Allergy Academies. Optimization and simplification of the allergic and hypersensitivity conditions classification for the ICD-11. Allergy. 2016;71:671-6.

21. Tanno LK, Calderon MA, Demoly P, on behalf the Joint Allergy Academies. New allergic and hypersensitivity conditions section in the International Classification of Diseases-11. Allergy Asthma Immunol Res. 2016;8:383-8. 
22. Tanno LK, Calderon MA, Papadopoulos NG, Sanchez-Borges M, Rosenwasser $\sqcup$, Bousquet J, et al. Revisiting desensitization and allergen immunotherapy concepts for the International Classification of Diseases (ICD)-11. J Allergy Clin Immunol Pract. 2016:4:643-9.

23. Tanno LK, Calderon MA, Li J, Casale T, Demoly P. Updating allergy/ hypersensitivity diagnostic procedures in the WHO ICD-11 revision. J Allergy Clin Immunol Pract. 2016:4:650-7.

24. Tanno LK, Calderon MA, Papadopoulos NG, Sanchez-Borges M, Moon HB, Sisul JC, Jares EJ, Sublett UL, Casale T, Demoly P, Joint Allergy Academies. Surveying the new allergic and hypersensitivity conditions chapter of the International classification of diseases (ICD)-11. Allergy. 2016;71(9):1235-40.

25. Tanno LK, Calderon M, Demoly P, Joint Allergy Academies. Supporting the validation of the new allergic and hypersensitivity conditions section of the World Health Organization International Classification of Diseases-11. Asia Pac Allergy. 2016;6(3):149-56.

26. World Health Organization, ICD-11 Beta Draft website. (cited, available: http://apps.who.int/classifications/icd1 1/browse/f/en. July 2016).

27. World Health Organization, ICD-10 version 2016 website. Cited, available: http://apps.who.int/classifications/icd10/browse/2016/en. Accessed Jul 2016

28. Tanno LK, Bierrenbach AL, Calderon MA, Sheikh A, Simons FE, Demoly P; on behalf of the Joint Allergy Academies. Decreasing the under-notification of anaphylaxis deaths in Brazil through the International Classification of Diseases (ICD)-11 revision. Allergy. 2016 Aug 18. doi:10.1111/all.13006.

29. Barnard JH. Studies of 400 Hymenoptera sting deaths in the United States. J Allergy Clin Immunol. 1973;52:259-64.

30. Bock SA, Muñoz-Furlong A, Sampson HA. Fatalities due to anaphylactic reactions to foods. J Allergy Clin Immunol. 2001;107:191-3.

31. Delage C, Irey NS. Anaphylactic deaths: a clinicopathologic study of 43 cases. J Forensic Sci. 1972;17:525-40.

32. James LP, Austen KF. Fatal systemic anaphylaxis in man. N Engl J Med. 1964;270:597-603.

33. Jerschow E, Lin RY, Scaperotti MM, McGinn AP. Fatal anaphylaxis in the United States, 1999-2010: Temporal patterns and demographic associations. J Allergy Clin Immunol. 2014;134:1318-28. e7.

34. Lenler-Petersen P, Hansen D, Andersen M, Sørensen HT, Bille H. Drug-related fatal anaphylactic shock in Denmark 1968-1990. A study based on notifications to the Committee on Adverse Drug Reactions. J Clin Epidemiol. 1995;48:1185-8.

35. Low I, Stables S. Anaphylactic deaths in Auckland, New Zealand: a review of coronial autopsies from 1985 to 2005. Pathology. 2006;38:328-32.

36. Ma L, Danoff TM, Borish L. Case fatality and population mortality associated with anaphylaxis in the United States. J Allergy Clin Immunol. 2014;133:1075-83.

37. Mosbech H. Death Caused by wasp and bee sting in Denmark 1960-1980. Allergy. 1983;38:195-200

38. Pumphrey RHS, Roberts ISD. Postmortem findings after fatal anaphylactic reactions. J Clin Pathol. 2000;53:273-6.

39. Sampson HA, Mendelson L, Rosen JP. Fatal and near-fatal anaphylactic reactions to food in children and adolescents. N Engl J Med. 1992;327:380-4.

40. Savary T, Muller U. Deaths from insect stings in Switzerland. Schweiz Med Wochenschr. 1994;124:1887-94.

41. Simon MR, Mulla ZD. A population-based epidemiologic analysis of deaths from anaphylaxis in Florida. Allergy. 2008;63:1077-83.

42. Turner PJ, Gowland MH, Sharma V, lerodiakonou D, Harper N, Garcez T, Pumphrey R, Boyle RJ. Increase in anaphylaxis-related hospitalizations but no increase in fatalities: An analysis of United Kingdom national anaphylaxis data, 1992-2012. J Allergy Clin Immunol. 2015;135:956-63. e1.

43. Yunginger JW, Sweeney KG, Sturner WQ, Giannandrea LA, Teigland JD, et al. Fatal food-induced anaphylaxis. JAMA. 1988;260:1450-2.

44. Yunginger JW, Nelson DR, Squillace DL, Jones RT, Holley KE, Hyma BA, Biedrzycki L, Sweeney KG, Sturner WQ, Schwartz LB. Laboratory investigation of deaths due to anaphylaxis. J Forensic Sci. 1991;36:857-65.

\section{Submit your next manuscript to BioMed Central and we will help you at every step:}

- We accept pre-submission inquiries

- Our selector tool helps you to find the most relevant journal

- We provide round the clock customer support

- Convenient online submission

- Thorough peer review

- Inclusion in PubMed and all major indexing services

- Maximum visibility for your research

Submit your manuscript at www.biomedcentral.com/submit
Biomed Central 